\title{
PENGOLAHAN DATA MIKROTREMOR BERDASARKAN METODE HVSR DENGAN MENGGUNAKAN MATLAB
}

\author{
Winda Styani Yuliawati ${ }^{1}$, Syamsurijal Rasimeng ${ }^{2}$ Karyanto $^{3}$ \\ 1,2,3 J1. Prof. Dr. SumantriBrojonegoro No.1 Bandar Lampung 35145 \\ Jurusan Teknik Geofisika, FT UNILA
}

Corresponding author: windastyaniyuliawati@gmail.com

Manuscript received: June 15, 2018; revised: October 1, 2018;

Approved: December 3, 2018; available online: March 1, 2019

\begin{abstract}
Abstrak - Telah dilakukan penelitian yang menghasilkan sebuah program matlab untuk pengolahan data mikrotremor. Penelitian ini bertujuan untuk menerapkan software matlab ke dalam pengolahan data mikrotremor. Mikrotremor adalah getaran tanah yang dapat mengidentifikasi kerentanan gempa bumi dengan menggunakan metode HVSR (Horizontal to Vertikal Spectral Ratio). Metode HVSR (Horizontal to Vertikal Spectral Ratio) merupakan metode untuk membandingkan dua komponen horizontal terhadap komponen vertikal pada gelombang mikrotremor yang akan menghasilkan nilai frekuensi dominan $\left(f_{0}\right)$ berdasarkan nilai spektrum $H / V$ tertinggi dari analisis kurva HVSR. Berdasarkan dari penelitian tersebut disimpulkan bahwasannya pengolahan data mikrotremor dapat dilakukan dengan software matlab, hasil dari pengolahan data ini akan menghasilkan nilai yang tidak jauh berbeda dengan software geopsy. Nilai frekuensi dominan yang dihasilkan oleh software geopsy dan matlab masuk ke dalam site class jenis 2 yaitu sebagian besar adalah aluvium. Sedangkan dari nilai periode dominan yang dihasilkan oleh software geopsy dan matlab masuk ke dalam site class jenis 1 dengan jenis lapisan tanah yang keras.
\end{abstract}

\begin{abstract}
The research has conducted to get the result of Matlab program for microtremor data processing. The purpose of this research is to apply Matlab software into microtremor data processing. The microtremor is the ground motion to identify earthquake vulnerability by using HVSR (Horizontal to Vertical Spectral Ratio) method. The HVSR method for comparing both of horizontal component and vertical component on microtremor wave to obtain the result dominant frequency(f0) based on the high spectrum H/V value from the analysis of HVSR curve. Based on this research which concludes that microtremor data processing has processed using Matlab software. The result of this data processing gives similar value from the geopsy software. The value of dominant frequency by Matlab software and geopsy software calculation are classified on the site class type II which is dominantly alluvium. Whereas, the result of dominant period by geopsy and Matlab are classified on the site class type I which shows as the bedrock.
\end{abstract}

Keywords-Software Matlab, Microtremor, HVSR, Frequency

How to cite this article:

Yuliawati, W. S., Rasimeng, S., dan Karyanto. 2019. Pengolahan Data Mikrotremor Berdasarkan Metode HVSR Dengan Menggunakan Matlab. Jurnal Geofisika Eksplorasi, 5 (1) p.45-59. doi: 10.23960/jge.v5i1.22

\section{PENDAHULUAN}

\subsection{Latar Belakang}

Matlab adalah bahasa pemograman yang dikhususkan untuk pemograman, komputa-si numerik dan visualisasi. Penelitian ini menggunakan software matlab untuk me-ngolah data mikrotremor. Penerapan software matlab untuk pengolahan data ini sering sekali dilakukan, hal ini dikarenakan pengolahan dengan software matlab ini lebih efektif, mudah, menyediakan fasilitas untuk memplot struktur, script program yang dapat diubah sesuai dengan keinginan user dan lain-lain.

Metode yang digunakan pada penelitian ini adalah metode HVSR (Horizontal to Vertical Spectrum Ratio) yang merupakan metode untuk mengetahui karakteristik tanah dengan membandingkan 
spektrum horizontal dan spektrum vertikal. Metode HVSR tersebut akan menghasilkan nilai frekuensi dominan berdasarkan analisis kurva HVSR yang dihasilkan, selanjutnya akan dapat menghitung pula nilai periode dominannya.

Penelitian ini bertujuan untuk merealisasikan pengolahan data mikrotremor dengan menggunakan Matlab yang berguna untuk mengetahui nilai frekuensi dominan, periode dominan, amplifikasi dan percepatan gerak tanah maksimum di suatu wilayah. Hal ini dilakukan agar dapat membandingkan hasil dari pengolahan dengan software geopsy dan matlab. Pengolahan yang dilakukan dengan software geospy ini kurang efektif karena terdapat beberapa tahapan yang harus dilalui dan diolah per satu titik. Sedangkan pada software matlab hanya dilakukan dengan sekali running, karena semua tahapan seperti proses FFT dan sebagainya sudah tercatat di dalam script.

Oleh sebab itu, penelitian ini membuat script pengolahan data mikrotremor dengan menggunakan pemograman matlab, supaya lebih efisiensi dalam pengolahan datanya yang digunakan untuk memetakan daerah yang rawan dari gempabumi.

\subsection{Tujuan Penelitian}

Tujuan dari penelitian ini adalah sebagai berikut:

1. Merealisasikan software matlab untuk pengolahan data penelitian.

2. Mengetahui nilai frekuensi, periode, amplifikasi dan Peak Ground Acceleration (PGA).

3. Membandingkan nilai frekuensi hasil dari software matlab dan software geopsy pada pengolahan data mikrotremor.

\section{TEORI DASAR}

\subsection{Transformasi Fourier}

Transformasi Fourier merupakan metode untuk analisis spektral dengan tujuan agar sinyal yang diperoleh dalam domain waktu diubah menjadi domain frekuensi. Hal ini dilakukan karena perhitungan lebih mudah dalam domain frekuensi dibandingkan dengan domain waktu. Selain itu, fenomena geofisika berkaitan erat dengan frekuensi, sehingga frekuensi menjadi parameter penting dalam menjelaskan fenomena-fenomena tersebut. Transformasi Fourier adalah dari sebuah fungsi $f(t)$ didefenisikan sebagai berikut:

$$
F(\omega)=\int_{-\infty}^{\infty} \mathrm{f}(\mathrm{t}) e^{-i \omega t} d t
$$

dimana $\omega=2 \pi f$ (variabel frekuensi sudut dengan satuan radian per detik) (Nasution, 2016).

\subsection{Sampling}

Sinyal analog a(t) merupakan fungsi kontinyu dari variable waktu kontinyu $t$. Sinyal analog disampling dengan waktu interval yang sarna dengan $T$ akan menghasilkan sinyal digital.

$$
X(n T)=\left.a(t)\right|_{t=n t}-\infty<n<\infty
$$

$T$ merupakan kebalikan dari rasio sampling, $F$.

Sampling merupakan salah satu proses yang sangat penting. Untuk melakukan sampling terhadap sinyal informasi harus memperhatikan penggunaan frekuensi sampling yang akan digunakan. Frekuensi sinyal sampling sendiri menurut teorema Nyquist adalah harus dua kali lebih besar dari frekuensi informasi $\left(f_{s}>2 * f i\right)$ dengan $f s$ adalah frekuensi sampling dan $f i$ adalah frekuensi informasi. Hal ini karena agar dihasilkan proses sampling yang baik. Jika frekuensi sampling lebih kecil daripada frekuensi informasi akan mengakibatkan sinyal hasil sampling rusak. Untuk membuat dan melihat proses sampling dapat menggunakan software MATLAB (Wahab, dkk., 2002).

\subsection{Interpolasi dengan Spline}

Interpolasi dengan polinomial sering memberikan hasil yang tak dapat diterima. Polinomial interpolasi yang dihasilkan dari 
sejumlah besar data titik biasanya berderajad tinggi. Polinomial berderajad tinggi biasanya bersifat osilatif (grafiknya naik turun secara cepat). Akibatnya, perubahan data pada interval kecil dapat menyebabkan fluktuasi yang besar pada keseluruhan interval. Karena alasan ini, biasanya interpolasi hanya menggunakan polinomial berderajad rendah. Dengan membatasi derajad polinomial interpolasi, diperoleh alternatif lain untuk mendapatkan sebuah kurva mulus yang melalui sejumlah titik. Hasilnya sebuah kurva yang terdiri atas potongan-potongan kurva polinomial yang berderajad sama. (Sahid, 2012).

\subsection{Mikrotremor}

Mikrotremor merupakan suatu metode geofisika untuk identifikasi bawah permukaan yang memanfaatkan getaran yang disebabkan oleh aktivitas manusia dan fenomena alam (aliran air, angin, variasi tekanan atmosfer, dan gelombang laut). Pengukuran mikrotremor pada umumnya sama seperti seismik, sinyal yang didapatkan dapat memberikan informasi seperti sumber gelombang, atenuasi gelombang, serta kondisi dari titik pengukuran. Misalnya untuk monitoring unconventional reservoirs seperti shale gas, mikrotremor sangat penting untuk melakukan karakteristik retakan dan untuk mengetahui potensi produksi sumur kedepannya (Zheng, dkk., 2016).

\subsection{HVSR (Horizontal to Vertical Spectrum Ratio)}

Metode HVSR merupakan metode membandingkan spektrum komponen horizontal terhadap komponen vertikal dari gelombang mikrotremor. Mikrotremor terdiri dari ragam dasar gelombang Rayleigh, periode puncak perbandingan $H / V$ mikrotremor memberikan dasar dari periode gelombang $\mathrm{S}$ (S-wave). Perbandingan $H / V$ pada mikrotremor merupakan perbandingan dua komponen yang secara teoritis menghasilkan suatu nilai. Metode HVSR digunakan untuk menentukan nilai amplifikasi dan nilai periode dominan suatu lokasi yang dapat diperkirakan dari periode puncak perbandingan $H / V \quad$ mikrotremor (Nakamura, 2000).

$$
\frac{H}{V}=\frac{\sqrt{H x^{2}+H y^{2}}}{H z}
$$

Dimana $H x$ adalah rasio horizontal $\mathrm{x}, H y$ adalah rasio horizontal y dan $\mathrm{Hz}$ adalah rasio vertikal $\mathrm{z}$.

\subsection{Frekuensi Dominan}

Frekuensi didefinisikan secara sederhana sebagai kebalikan dari waktu. Sehingga waktu yang satuannya adalah detik (second) akan menjadi Hertz (1-per second) hanya akan memiliki tepat satu nilai spektrum. Yang dikenal dengan spektrum frekuensi. Pengertian frekuensi ini juga berlaku untuk gelombang monokromatis. Frekuensi dominan adalah nilai frekuensi yang kerap muncul sehingga diakui sebagai nilai frekuensi dari lapisan batuan di wilayah tersebut sehingga nilai frekuensi dapat menunjukkan jenis dan karakterisktik batuan tersebut (Lachet dan Brad, 1994).

\subsection{Amplifikasi}

Amplifikasi merupakan perbesaran gelombang seismik yang terjadi akibat adanya perbedaan yang signifikan antar lapisan, dengan kata lain gelombang seismik akan mengalami perbesaran, jika merambat pada suatu medium ke medium lain yang lebih lunak dibandingkan dengan medium awal yang dilaluinya. Semakin besar perbedaan itu, maka perbesaran yang dialami gelombang tersebut akan semakin besar. Nilai faktor penguatan (amplifikasi) tanah berkaitan dengan perbandingan kontras impedansi lapisan permukaan dengan lapisan di bawahnya. Bila perbandingan kontras impedansi kedua lapisan tersebut tinggi maka nilai faktor penguatan juga tinggi, begitu pula sebaliknya (Nakamura, 2000).

Fujimoto dan Midorikawa (2006) menyarankan hubungan antara $V s 30$ dan faktor amplifikasi (ampv) dengan 
persamaan sebagai berikut (Morikawa dkk, 2008):

$$
\log (a m p v)=2,367-0,852 \log \left(V_{s} 30\right)
$$

Dimana $V s 30$ adalah kecepatan gelombang shear pada kedalaman $30 \mathrm{~m}(\mathrm{~m} / \mathrm{s})$ dan $A m p v$ adalah faktor amplifikasi.

\subsection{PGA (Peak Ground Acceleration)}

Setiap gempa yang terjadi menimbulkan suatu pergerakan tanah, besarnya percepatan tanah sangat penting dalam kaitannya dengan perencanaan pembangunan. Semakin besar nilai PGA suatu tempat maka potensi kerusakan yang terjadi semakin parah jika terjadi gempabumi. Pengukuran nilai PGA secara empiris dapat dilakukan dengan pendekatan beberapa persamaan yang diturunkan dari magnitudo dan intensitas gempabumi. Salah satu perumusan nilai PGA dengan formula Kanai:

$$
P G A=\frac{5}{\sqrt{T}} 10^{0,61 M-P \log R+Q}
$$

Dengan $P$ dan $Q$ berturut-turut adalah:

$$
\begin{aligned}
& P=1,66+\frac{3,6}{R} \\
& Q=0,167-\frac{1,83}{R}
\end{aligned}
$$

Dimana $P G A$ adalah percepatan getaran (gal), $T$ Periode dominan (detik), $M$ Magnitudo gelombang permukaan (SR) dan $R$ Jarak Hiposenter (Km).

\section{METODE PENELITIAN}

\subsection{Alat dan Bahan}

Adapun alat dan bahan yang digunakan dalam kerja praktek ini adalah sebagai berikut:

- Laptop

- Software Matlab 2013

- Software Microsoft Word dan Microsoft Excel 2007

\subsection{Prosedur pembuatan script matlab untuk pengolahan data mikrotremor} Penelitian ini membuatscript matlab untuk pengolahan data mikrotremor adapun tahapannya yaitu sebagai berikut:

\subsubsection{Pembacaan Data Pengukuran}

Pada proses ini dilakukan loading atau read data dengan menggunakan teori matriks. Data dari penelitian ini berupa data waktu, komponen $\mathrm{x}$, komponen $\mathrm{y}$, dan komponen z. Hasil pembacaan data tersebut akan menghasilkan sinyal data pada setiap komponen dengan menggunakan proses plotting.

\subsubsection{Proses penentuan nilai frekuensi dengan proses FFT}

Pada proses ini penentuan nilai frekuensi menggunakan fungsi FFT (Fast Fourier Transform). FFT (Fast Fourier Transform) adalah salah satu fungsi perubahan dari data pengukuran yang merupakan domain waktu ke domain frekuensi.

\subsubsection{Pengolahan nilai $H / V$ dengan matlab}

Proses perhitungan untuk mendapatkan nilai $H / V$ dilakukan dengan beberapa tahap yaitu tahapan yang pertama adalah proses Fast Fourier Transform (FFT), proses ini dilakukan untuk mengubah domain waktu pengukuran ke domain frekuensi. Proses ini dilakukan untuk semua komponen yaitu dua nilai spektrum horizontal (E-W dan S-N) dan spektrum vertikal. Kemudian perhitungan nilai $H / V$, nilai $H / V$ adalah perbandingan nilai spektrum horizontal dan spektrum vertikal. Sehingga akan dihasilkan nilai $H / V$ yang mana akan digunakan untuk analisis kurva $H V S R$ untuk mengetahui nilai frekuensi dominan. 
3.2.4 Plotting kurva HVSR untuk penentuan nilai frekuensi dominan

Setelah menghitung nilai $H / V$, selanjutnya melakukan plotting kurva HVSR untuk mengetahui nilai frekuensi dominan. Nilai frekuensi dominan ditentukan dari analisis hasil kurva HVSR, yang mana nilai frekuensi dominan ditunjukkan dari puncak tertinggi kurva. Setelah didapatkan nilai frekuensi tersebut maka dapat dilakukan perhitungan untuk mengetahui nilai periode dominan.

\subsubsection{Pengolahan nilai amplifikasi dengan data $V s 30$}

Nilai amplifikasi ini digunakan untuk mengetahui penguatan gelombang di daerah penelitian. Nilai amplifikasi ini didapatkan dari dengan mengetahui nilai $V s 30$ daerah penelitian. Data $V s 30$ yang digunakan adalah data $V_{s} 30$ yang diambil dari USGS (United States Geological Survey).

\subsubsection{Pengolahan nilai PGA dengan persamaan Kanai 1966}

Pengolahan nilai PGA ini dilakukan dengan beberapa analisis dan perhitungan, salah satu perumusan nilai PGA dengan formula Kanai terdapat dipersamaan $(5,6$ dan 7).

\subsection{Diagram Alir Penelitian}

Diagram alir dari penelitian ini adalah seperti pada (Gambar 1) di lampiran.

\section{HASIL DAN PEMBAHASAN}

\subsection{Pengolahan data mikrotremor dengan software matlab}

Pengolahan data mikrotremor pada penelitian ini dilakukan dengan menggunakan software matlab. Dalam pengolahan data ini terdapat penentuan parameter yang harus sesuai agar menampilkan hasil yang lebih baik. Pengolahan data mikrotremor ini dilakukan dalam beberapa tahap yaitu tahapan pertama melakukan pembacaan data yang akan menghasilkan plotting grafik 3 komponen. Pembacaan data pada matlab berdasarkan teori matematis dari matriks dimana membaca kolom dan baris. Pada penelitian ini matriks data adalah 4 kolom dan $n$ baris. Matriks 4 kolom yaitu adalah nilai waktu, komponen data pengukuran $x$, $y$ dan $z$.

Pada plotting grafik 3 komponen ini dilakukan dengan load data pengukuran kemudian pemisahan nilai $t$ (waktu) dan nilai 3 komponen $(x, y$, dan $z$ ). Selanjutnya melakukan plotting antara waktu dan salah satu komponen seperti plot $(t, x)$ dan sebagainya, hal ini juga berlaku untuk komponen $y$ dan $z$. Script pembacaan data pengukuran terdapat pada (Gambar 2).

Berdasarkan script pengolahan data tersebut, sehingga akan menghasilkan grafik hasil plotting seperti pada (Gambar 3) di bawah ini.

Pada (Gambar 3) di atas adalah grafik pengukuran yang mana garis horizontal menunjukkan nilai waktu pengukuran sedangkan untuk garis vertikal menunjukkan nilai amplitudo gelombang pada komponen X, Y dan Z. Ketiga grafik memiliki nilai amplitudo dan waktu yang berbeda-beda.

Tahapan yang kedua yaitu melakukan proses FFT (Fast Fourier Transform), proses ini adalah proses pengubahan sinyal dalam domain waktu ke domain frekuensi atau untuk menentukan kandungan frekuensinya. Domain waktu (periode) didefinisikan sebagai waktu yang dibutuhkan gelombang untuk mencapai suatu gelombang penuh. Domain frekuensi didefinisikan sebagai jumlah gelombang yang terjadi dalam 1 detik. Frekuensi secara sederhana merupakan kebalikan dari waktu, sehingga waktu yang satuannya adalah detik (second) akan menjadi Hertz (1 per second) hanya akan memiliki tepat satu nilai spektrum.

Pengubahan sinyal atau gelombang dari domain waktu ke domain frekuensi ini dilakukan karena perhitungan lebih mudah dalam domain frekuensi dibandingkan dengan domain waktu. Selain itu, dalam 
geofisika berkaitan erat dengan frekuensi, sehingga frekuensi menjadi parameter penting. Proses FFT ini dilakukan dengan pengubahan nilai waktu pada data pengukuran menjadi nilai frekuensi, yang mana nilai frekuensi ini akan digunakan dalam pembuatan kurva HVSR yang akan diplotting dengan nilai $H / V$.

Tahapan selanjutnya yaitu penentuan nilai absolute, nilai absolute ini digunakan agar hasil dari proses FFT (Fast Fourier Transform) bernilai mutlak. Hal ini dilakukan untuk mempermudah dalam proses perhitungan, adapun persamaannya terdapat dalam (flow chart pengolahan matlab). Nilai real dan imajiner termasuk kedalam bilangan kompleks. Bilangan real adalah bilangan yang merupakan gabungan dari bilangan rasional dan bilangan irrasional sendiri. Bilangan Rasional yaitu bilangan dalam bentuk $a / b$, dengan $a$ dan $b$ anggota bilangan bulat dan $b \neq 0$ sedangkan bilangan irrasional adalah bilangan yang tidak bisa dikatakan sebagai pecahan. Pada (Gambar 4) di bawah ini merupakan script penentuan nilai FFT dan absolute pada pengolahan data penelitian ini.

Setelah itu plotting nilai frekuensi dengan nilai absolute $\mathrm{X}$, sehingga akan muncul seperti pada (Gambar 5). Kemudian dilakukan proses pemilihan nilai frekuensi, hal ini perlu dilakukan karena pada mikrotremor frekuensi yang dipakai hanya frekuensi terendah saja karena frekuensi tersebut yang menunjukkan kerentanan suatu wilayah terhadap gempa bumi. Berdasarkan pada (Gambar 5) frekuensi terendah ditunjukkan pada lingkaran berwarna merah. Selanjutnya membatasi nilai frekuensi yang diinginkan disesuaikan dengan frekuensi terendah pada gambar tersebut, sehingga untuk nilai frekuensi yang dipakai adalah sampai 350 Hz. Hal ini dikarena nilai tersebut adalah nilai terendah, karena frekuensi yang digunakan untuk penentuan kerentanan terhadap gempa bumi adalah frekuensi yang rendah. Sehingga pengolahan pada penelitian ini memilih nilai frekuensi terendah.

Selanjutnya penentuan frekuensi, frekuensi sampling ini digunakan untuk memotong atau mencuplikan sinyal gelombang pada sumbu $x$. Frekuensi sinyal sampling sendiri menurut teorema Nyquist adalah harus dua kali lebih besar dari frekuensi informasi $\left(\mathrm{f}_{\mathrm{s}}>\mathrm{f}_{\mathrm{i}}\right)$ dengan $f s$ adalah frekuensi sampling dan $f i$ adalah frekuensi informasi. Hal ini karena agar dihasilkan proses sampling yang baik.

Jika frekuensi sampling lebih kecil daripada frekuensi informasi akan mengakibatkan sinyal hasil sampling rusak atau aliasing. Fenomena aliasing proses sampling akan muncul pada sinyal hasil sampling apabila proses frekuensi sinyal sampling tidak memenuhi kriteria. Pada pengolahan ini menggunakan nilai frekuensi sampling $100 \mathrm{~Hz}$. Penentuan ini didasarkan karena nilai frekuensi tanah berkisar $0.2 \mathrm{~Hz}$ sampai $20 \mathrm{~Hz}$. Oleh sebab itu, nilai frekuensi sampling yang digunakan adalah $100 \mathrm{~Hz}$.

Pada gambar di bawah ini (Gambar 6) adalah script formula perhitungan frekuensi dan spektrum $H / V$ untuk kemudian diplotting dengan nilai spektrum $H / V$, sehingga akan menghasilkan kurva HVSR.

Pada (Gambar 7) di bawah ini menunjukan persebaran data hasil proses FFT (Fast Fourier Transform) pada frekuensi rendah. Berdasarkan (Gambar 8) persebaran data berada dinilai 0-4 di sumbu $Y$ dan di sumbu $X$ tersebar pada nilai $0-3$ Hz. Sedangkan nilai yang berada dibatasan tersebut kemungkinan adalah noise, sehingga persebaran nilainya sangat jauh dengan nilai yang lain.

Tahapan selanjutnya yaitu menghitung nilai rasio $H / V$. Nilai rasio $H / V$ ini didapatkan dari akar dari penjumlahan 2 komponen horizontal yaitu komponen $\mathrm{x}$ kuadrat dan komponen y kuadrat dan kemudian dibagi dengan komponen vertikal. Kurva HVSR ini digunakan untuk penentuan nilai frekuensi dominan $\left(f_{0}\right)$ 
dengan menentukan nilai rasio dari vertikal dan horizontal dengan cara menarik garis lurus ke bawah dari puncak rasio kurva HVSR yang tinggi sehingga akan didapatkan nilai frekuensinya.

Proses penentuan frekuensi dominan (fo) dilakukan dengan plotting nilai frekuensi dengan nilai spektrum rasio $H / V$. Di bawah ini adalah grafik kurva HVSR (Gambar 8). Terdapat beberapa proses untuk menghasilkan kurva HVSR tersebut, antara lain adalah proses pick atau pemilihan data (windowing data).

Proses ini sangat penting dilakukan karena untuk menghilangkan noise atau sinyal gelombang yang peak (tinggi). Selain itu melakukan interpolasi spline, proses ini akan menghasilkan fungsi polinomial baru yang merupakan potongan dari fungsi polinomial kecil berderajat tiga yang akan saling sambung-menyambung sehingga dapat menghubungkan dua titik yang bersebelahan. Selanjutnya proses linspace, proses ini dilakukan untuk pencacahan dari data pertama sampai data terakhir sebanyak data yang diinginkan, misalnya linspace $(0,5,100)$ artinya batas 0 merupakan batas bawah, 5 merupakan batas atas, dan 100 merupakan jumlah data. Proses linspace ini juga dapat membuat grafik lebih smoothing dengan mengatur jumlah datanya, semakin banyak jumlah data yang ingin dilinspace maka akan semakin smooth grafik. Selanjutnya proses fnval, proses ini dilakukan untuk interpolasi data sehingga akan membuat kurva HVSR seperti pada (Gambar 8). Karena proses ini menggunakan interpolasi B-Spline. Kemudian melakukan plotting antara fungsi linspace dan fnval. Maka akan dihasilkan kurva HVSR seperti pada (Gambar 8).

Setelah didapatkan nilai frekuensi tersebut kemudian melakukan pengolahan nilai periode yaitu (1/f) sehingga akan didapatkan nilai periode.

Kemudian melakukan pengolahan nilai PGA, nilai PGA dapat dihitung dengan mengetahui koordinat sumber gempa, magnitudo dan kedalamannya. Penelitian ini menggunakan gempa referensi jogja yang diketahui sumber gempa, magnitudo gempa dan kedalaman gempa yang berturut-turut adalah $(\mathrm{X}=440265,7$ dan $\mathrm{Y}=$ 9119864), 6,3 SR dan 12,5 Km. Script pengolahan nilai PGA terdapat pada (Gambar 9).

Tahapan selanjutnya yaitu menghitung nilai amplifikasi, nilai amplifikasi dapat dihitung dengan mengetahui terlebih dahulu nilai Vs30 atau kecepatan gelombang $\mathrm{S}$ di kedalaman $30 \mathrm{~m}$. Selanjutnya dihitung nilai amplifikasinya.

\subsection{Perbandingan hasil dari software geopsy dan matlab}

Penelitian ini akan membandingkan hasil dari dua software yaitu software geopsy dan matlab. Di bawah ini adalah hasil nilai frekuensi, periode, dan PGA yang diolah dengan software geopsy dan matlab (Tabel 3) dan (Gambar 14). Serta pada (Tabel 4) adalah nilai error dari kedua software.

Berdasarkan pada (Gambar 14) tersebut dapat dibandingkan bahwasannya nilai yang diolah dengan software geopsy dan matlab hanya memiliki perbedaan nilai yang kecil. Hal ini dikarenakan setiap software memiliki ketelitian nilai yang berbeda-beda.

Pada nilai frekuensi sendiri memiliki perbedaan yang tidak signifikan, perbedaan ini terjadi karena pengaruh pada proses pengolahan. Pengaruh yang pertama karena proses windowing, proses windowing ini maksudnya adalah menghilangkan sinyalsinyal gelombang yang memiliki peak yang tinggi. Pada software geopsy proses windowing dilakukan dengan pemilihan gelombang yang terlalu speak secara automatis dengan menggunakan metode algoritma anti-triggering, sedangkan pada software matlab proses windowing dilakukan dengan pemilihan titik pada nilai disumbu $\mathrm{x}$ dan $\mathrm{y}$.

Selain itu juga karena proses FFT (Fast Fourier Transform) pada software geopsy menggunakan algoritma smoothing yang diusulkan oleh Krono dan Ohmachi dengan koefisien bandwith sebesar 40. Sedangkan 
pada software matlab melakukan proses FFT yang kemudian tahapan akhirnya yaitu proses linspace dan melakukan interpolasi spline. Namun, kelebihan dari software matlab ini dapat melakukan pengolahan data secara langsung sesuai script yang dibuat dan hanya merunning data selama beberapa detik saja dengan menggunakan fungsi "Tic dan Toc" dan dapat langsung disave sesuai format yang diinginkan, sedangkan untuk software geopsy banyak tahapan yang perlu dilakukan dalam pengolahan data dan pengolahan data dilakukan secara manual atau hanya satu titik saja yang bisa diolah. Selain itu juga nilai frekuensi dominan yang dihasilkan pada geopsy ditulis manual di surfer untuk kemudian digunakan untuk pengolahan selanjutnya.

Berdasarkan klasifikasi kanai (Tabel 1 dan Tabel 2) nilai frekuensi dominan dan periode dominan yang diolah dengan software geopsy dan matlab masuk kedalam klasifikasi site class yang sama sehingga menunjukkan bahwa data mikrotremor ini juga dapat diolah dengan software matlab. Pada nilai frekuensi dominan dikalsifikasikan ke dalam site class jenis 2 dengan kondisi tanah yaitu sebagian besar lapisan aluvium yang terdiri dari gravel, sandy clay dan lanau. Sedangkan untuk nilai periode dominan diklasifikasikan ke dalam site class Jenis 1 dengan kondisi tanah yaitu batuan tersier atau lebih tua dan terdiri dari batuan hard sandy dan gravel, dengan karakter lapisannya adalah keras.

\subsection{Analisis kurva HVSR (Horizontal to Vertical Spectra Ratio)}

Metode HVSR biasanya digunakan pada seismik pasif (mikrotremor) tiga komponen. Menurut Nakamura metode HVSR digunakan pada analisis mikrotremor untuk memperoleh frekuensi natural. Teknik HVSR (Horizontal to Vertical Spectral Ratio) pada analisis data mikrotremor telah digunakan secara luas untuk studi efek lokal dan mikrozonasi.

Data mikrotremor tersusun atas beberapa jenis gelombang, tetapi yang utama adalah gelombang Rayleigh yang merambat pada lapisan sedimen di atas batuan dasar. Pengaruh dari gelombang Rayleigh pada rekaman mikrotremor besarnya sama untuk komponen vertikal dan horizontal saat rentang frekuensi 0,2 hingga $20,0 \mathrm{~Hz}$ sehingga rasio spektrum antara komponen horizontal dan vertikal di batuan dasar mendekati nilai satu.

Kurva HVSR merupakan gabungan antara gelombang permukaan dan frekuensi resonansi gelombang yang menunjukkan bahwa frekuensi resonansi yang diestimasi dari gelombang sekunder dan gelombang rayleigh mempunyai nilai yang hampir sama, tetapi amplifikasinya yang berbeda.

Hasil dari pengolahan tersebut menghasilkan kurva seperti yang terlihat pada (Gambar 8). Berdasarkan gambar tersebut dapat dianalisis bahwasannya sumbu (x) menunjukkan nilai frekuensi $(\mathrm{Hz})$ sedangkan sumbu (y) menunjukkan nilai $H / V$. Nilai frekuensi dominan yang dihasilkan ditunjukkan pada titik nilai $H / V$ tertinggi atau puncak kurva. Sehingga hasil frekuensi dominan ( $\mathrm{f}_{0}$ ) yang ditunjukkan pada kurva (Gambar 8) adalah $1.489 \mathrm{~Hz}$ dengan nilai sumbu (y) adalah 1.79. Nilai inilah yang digunakan untuk analisis kegempaan berdasarkan nilai frekuensi terendah dengan metode HVSR (Horizontal to Vertical Spectra Ratio). Selanjutnya dari nilai frekuensi tersebut, dapat menghitung nilai periode dan PGA (Peak Ground Acceleration) sesuai dengan persamaanpersamaannya.

\section{KESIMPULAN DAN SARAN}

\subsection{Kesimpulan}

Berdasarkan hasil penelitian tersebut dapat disimpulkan sebagai berikut:

1. Pengolahan data mikrotremor untuk analisis kegempaan dapat dilakukan dengan menggunakan software matlab.

2. Nilai yang dihasilkan pada pengolahan data mikrotremor dengan software matlab tidak jauh berbeda dengan 
pengolahan yang dilakukan dengan software geopsy.

3. Nilai frekuensi dominan yang dihasilkan oleh software geopsy dan matlab masuk ke dalam site class jenis 2 yaitu sebagian besar adalah aluvium. Sedangkan dari nilai periode dominan yang dihasilkan oleh software geopsy dan matlab masuk ke dalam site class jenis 1 dengan jenis lapisan tanah yang keras.

\subsection{Saran}

Saran yang dapat diberikan dari penelitian ini perlu dibuatnya script matlab lanjutan yang dapat running seluruh file data pengukuran, karena penelitian ini hanya membuat script pengolahan untuk menjalankan satu titik pengukuran saja.

\section{UCAPAN TERIMA KASIH}

Penulis mengucapkan terima kasih kepada Bapak Syamsurijal Rasimeng S.Si., M.Si dan Karyanto, S.Si., M.T. sebagai pembimbing 1 dan pembimbing 2 yang telah banyak membimbing dan memberikan ilmu, saran, nasehat serta dukungan terhadap penyelesaian penelitian ini.

\section{DAFTAR PUSTAKA}

Lachet, C., dan Brad, P.,Y., 1994, Numerical and Theoretical Investigations on The Possibilities and Limitations of Nakamura's Technique, J, Phys, Earth, 42, 377397.

Morikawa, N., Senna, S., Hayakawa, Y., dan Fujiwara H., 2008, Application and Verification of The 'Recipe' to Strong-Motion Evaluation for The 2005 West Off Fukuoka Earthquake $(\mathrm{Mw}=6,6)$, Beijing: The 14th World Conference on Earthquake Engineering.

Nakamura, Y., 2000, Clear Indentification of Fundamental Idea of Nakamura's
Technique and Its Application, Tokyo University, Japan.

Nasution, A., H., 2016, Pemetaan Kecepatan Gelombang Geser (VS30) Menggunakan Metode MASW (Multichannel Analysis of Surface Wave) Kota Kalabahi Kabupaten Alor Nusa Tenggara Timur, Skripsi, Universitas Lampung, Lampung.

Sahid, 2012, Pengantar Komputasi Numerik, Universitas Negri Yogyakarta, Hl 247-251.

USGS-Earthquake, 2016, Situs Internet dari US, Geological Survey Earthquake Hazard Program, Alamat situs: (http://earthquake.usgs.gov/hazards/a pps/vs30/custom.php), 14 September 2016, Pukul 15.25 WIB.

Wartono., R.., 1995, Peta Geologi Lembar Yogyakarta, Pusat Penelitian dan Pengembangan Geologi.

Zheng, Y., Wang, Y., dan Chang, X., 2016, Wave Equation Based Microseismic Source Location and Velocity Inversion, Physics of the Earth and Planetary Interiors. 


\section{LAMPIRAN}

Tabel 1. Klasifikasi tanah oleh Kanai berdasarkan nilai frekuensi dominan mikrotremor (modifikasi) (Kanai, 1983).

\begin{tabular}{|c|c|c|c|}
\hline \multicolumn{2}{|c|}{1981 (Revised) } & 1950 & \multirow[b]{2}{*}{ Kondisi Tanah } \\
\hline Klasifikasi & $\begin{array}{c}\text { Frekuensi } \\
\text { Dominan }(\mathrm{Hz})\end{array}$ & Klasifikasi & \\
\hline Jenis 1 & $>5$ & Jenis 1 & $\begin{array}{l}\text { Batuan tersier atau lebih tua. Terdiri dari } \\
\text { batuan hard sandy, gravel. }\end{array}$ \\
\hline \multirow[t]{2}{*}{ Jenis 2} & \multirow[t]{2}{*}{$1,33-5$} & Jenis 2 & $\begin{array}{l}\text { Sebagian besar lapisan diluvium atau lapisan } \\
\text { aluvium dengan perbandingan ketebalan } \\
\text { lapisan gravelpada area yang luas. Terdiri } \\
\text { dari gravel, sandy hard clay dan loam. }\end{array}$ \\
\hline & & Jenis 3 & $\begin{array}{l}\text { Sebagian besar sangat didominasi oleh } \\
\text { lapisan aluvium. Terdiri dari sand, sandy clay } \\
\text { dan clay. }\end{array}$ \\
\hline Jenis 3 & $<1,33$ & Jenis 4 & $\begin{array}{l}\text { Tanah yang sangat lunak yang terbentuk pada } \\
\text { rawa dan lumpur. Terutama lapisan aluvium. }\end{array}$ \\
\hline
\end{tabular}

Tabel 2. Klasifikasi Tanah Kanai dan Omote - Nakajima (Kanai, 1983)

\begin{tabular}{|c|c|c|c|c|}
\hline \multicolumn{2}{|c|}{ Klasifikasi Tanah } & \multirow{2}{*}{$\begin{array}{l}\text { Periode } \\
\text { (T) } \\
\text { (sekon) }\end{array}$} & \multirow[b]{2}{*}{ Keterangan } & \multirow[b]{2}{*}{ Karakter } \\
\hline Kanai & $\begin{array}{l}\text { Omote - } \\
\text { Nakajima }\end{array}$ & & & \\
\hline Jenis I & \multirow[b]{2}{*}{ Jenis A } & $0,05-0,15$ & $\begin{array}{l}\text { Batuan tersier atau lebih tua. } \\
\text { Terdiri dari batuan hard } \\
\text { sandy, gravel, dll. }\end{array}$ & Keras \\
\hline Jenis II & & $0,10-0,25$ & $\begin{array}{l}\text { Batuan alluvial, dengan } \\
\text { ketebalan } 5 \mathrm{~m} \text {. Terdiri dari } \\
\text { sandy - gravel, sandy hard } \\
\text { clay, loam, dll. }\end{array}$ & Sedang \\
\hline Jenis III & Jenis B & $0,25-0,40$ & $\begin{array}{l}\text { Batuan alluvial, dengan } \\
\text { Ketebalan }>5 \mathrm{~m} \text {. Terdiri dari } \\
\text { sandy-gravel hard clay, loam, } \\
\text { dll. }\end{array}$ & Lunak \\
\hline Jenis IV & Jenis C & $>0,40$ & $\begin{array}{l}\text { Bahan alluvial, yang } \\
\text { terbentuk dari sedimentasi } \\
\text { delta, top soil, lumpur, dll. }\end{array}$ & $\begin{array}{l}\text { Sangat } \\
\text { Lunak }\end{array}$ \\
\hline
\end{tabular}




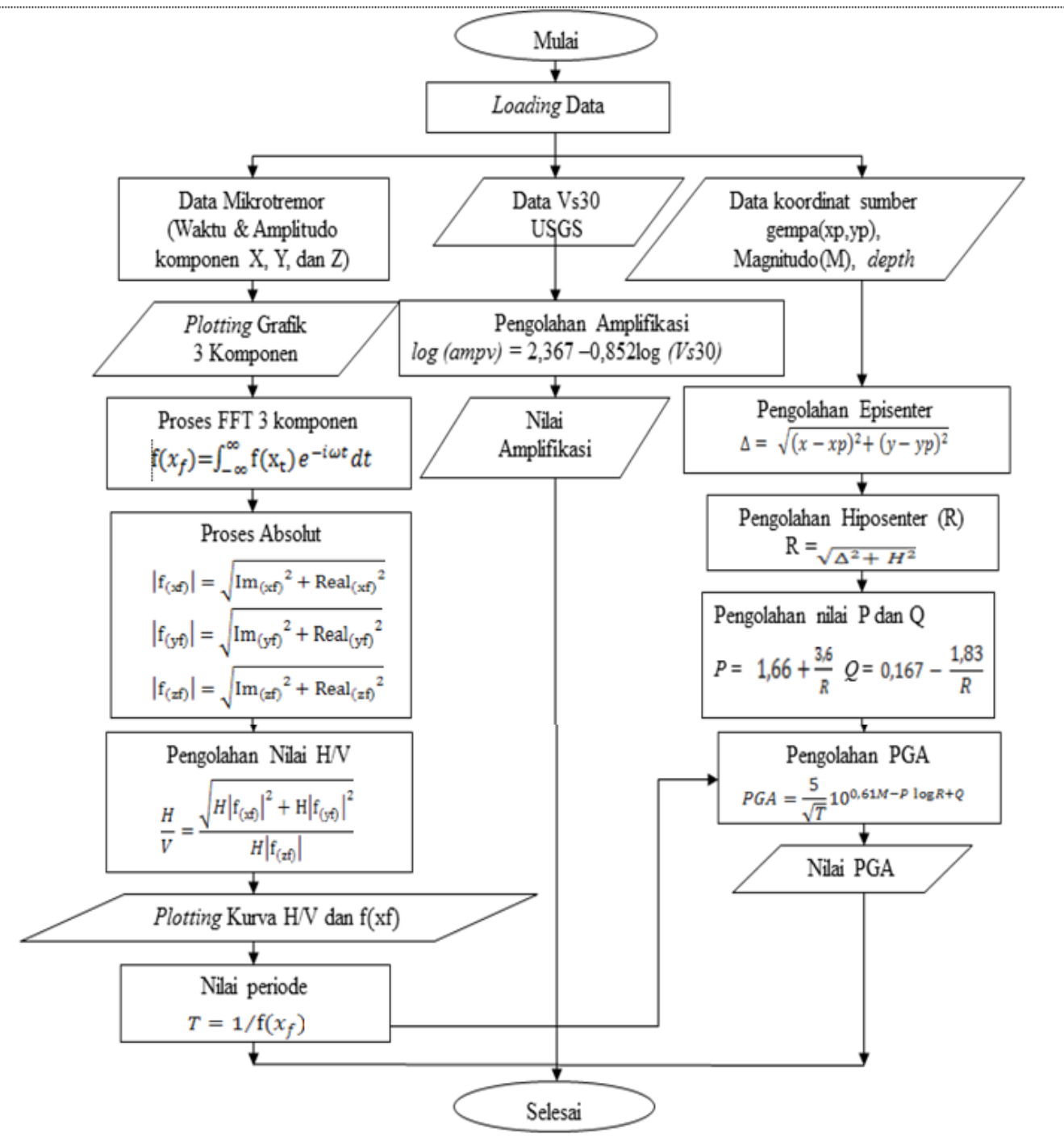

Gambar 1. Diagram alir penelitian

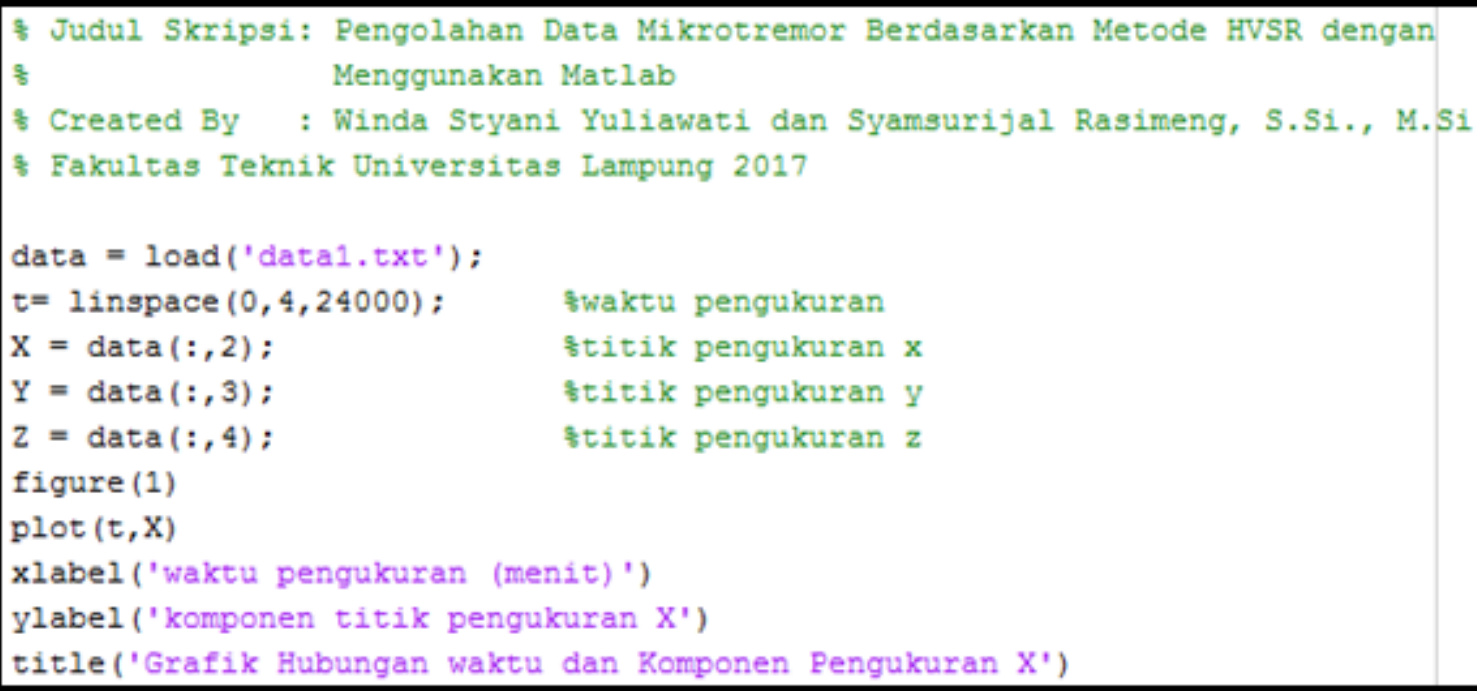

Gambar 2. Script pembacaan data pengukuran 

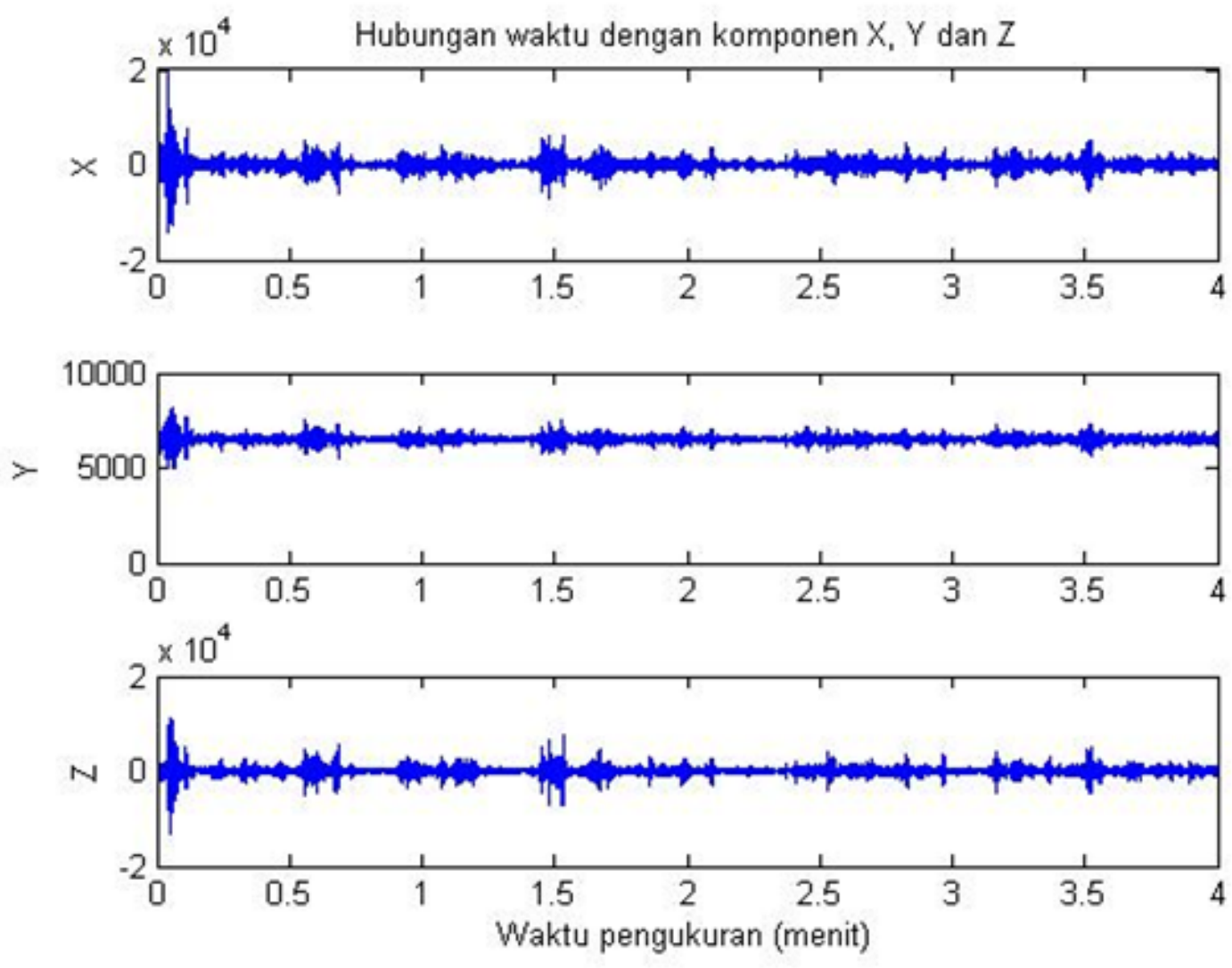

Gambar 3. Grafik hubungan waktu dan komponen titik pengukuran $\mathrm{X}, \mathrm{Y}$ dan $\mathrm{Z}$

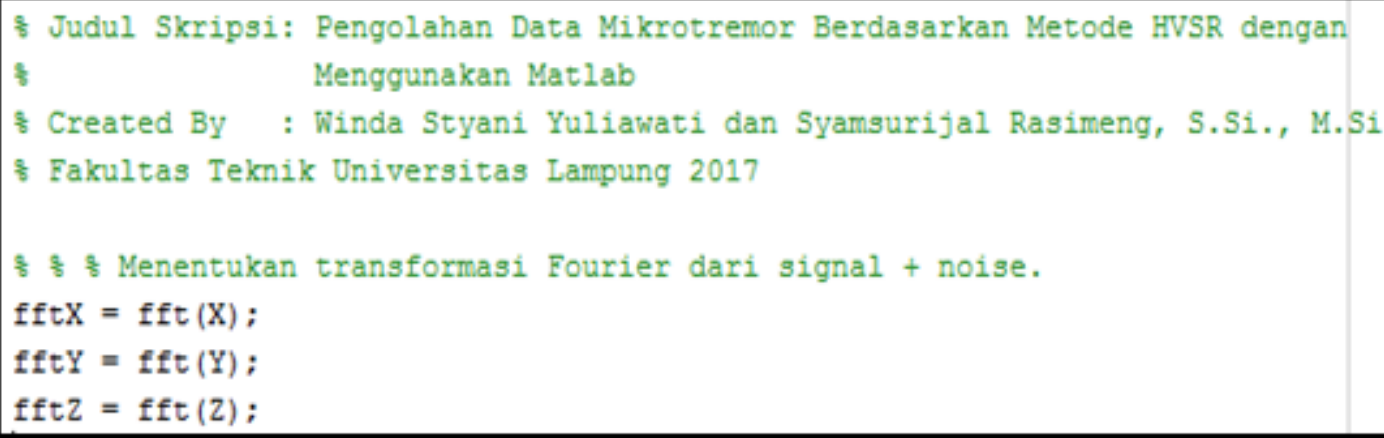

Gambar 4. Script proses FFT dan mencari nilai absolute 


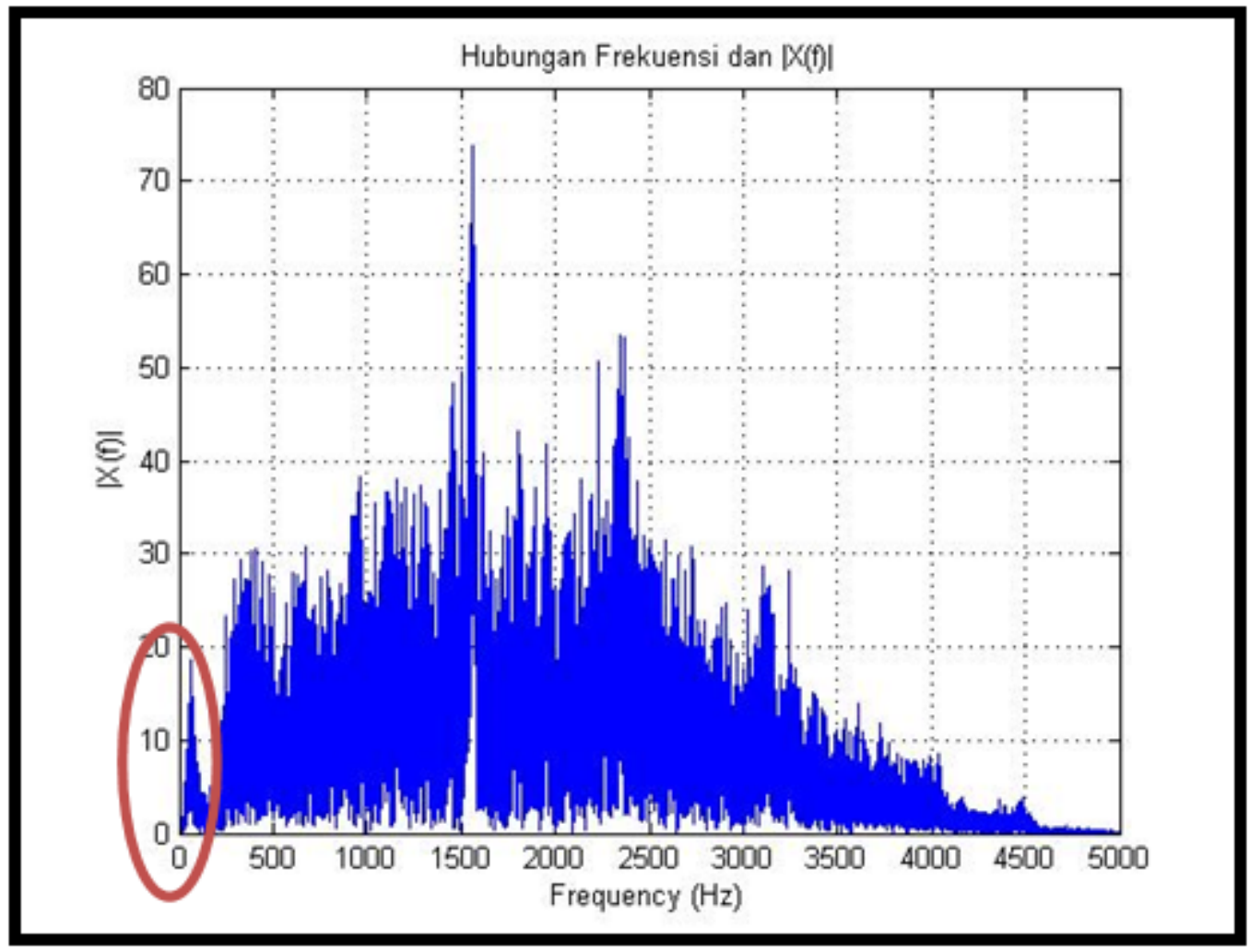

Gambar 5. Hubungan nilai frekuensi dan Abs $x$

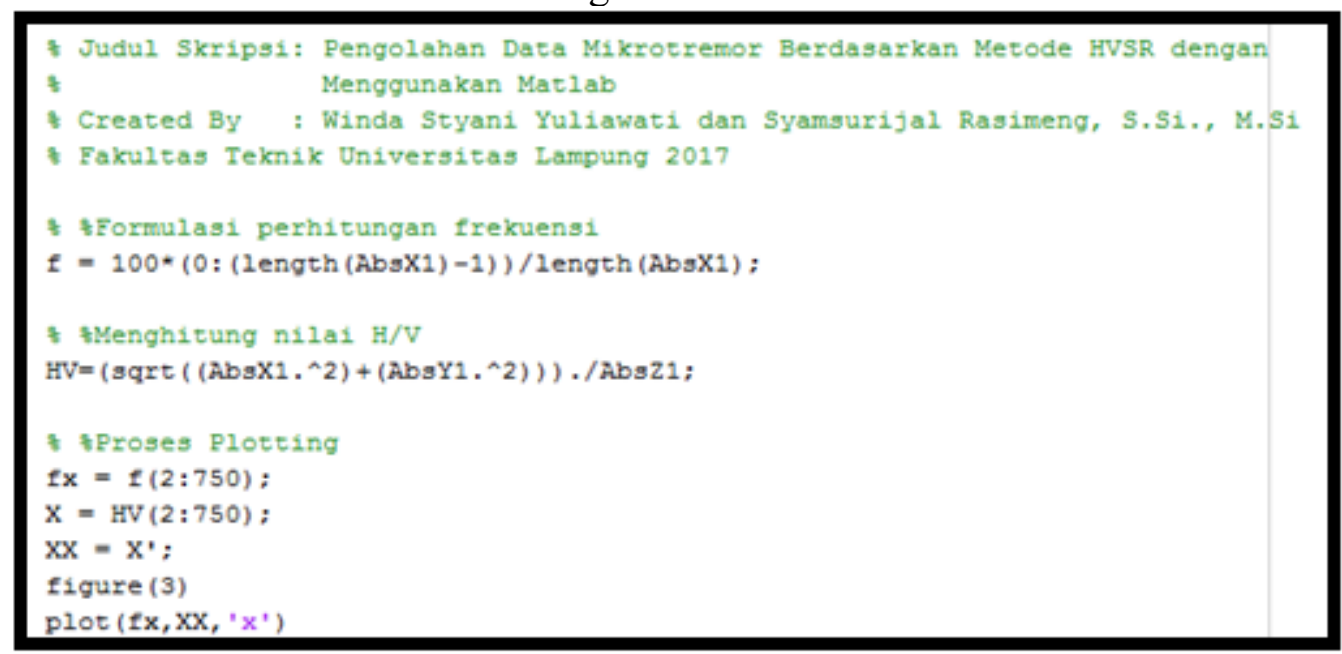

Gambar 6. Script perhitungan $H / V$ dan plotting kurva 


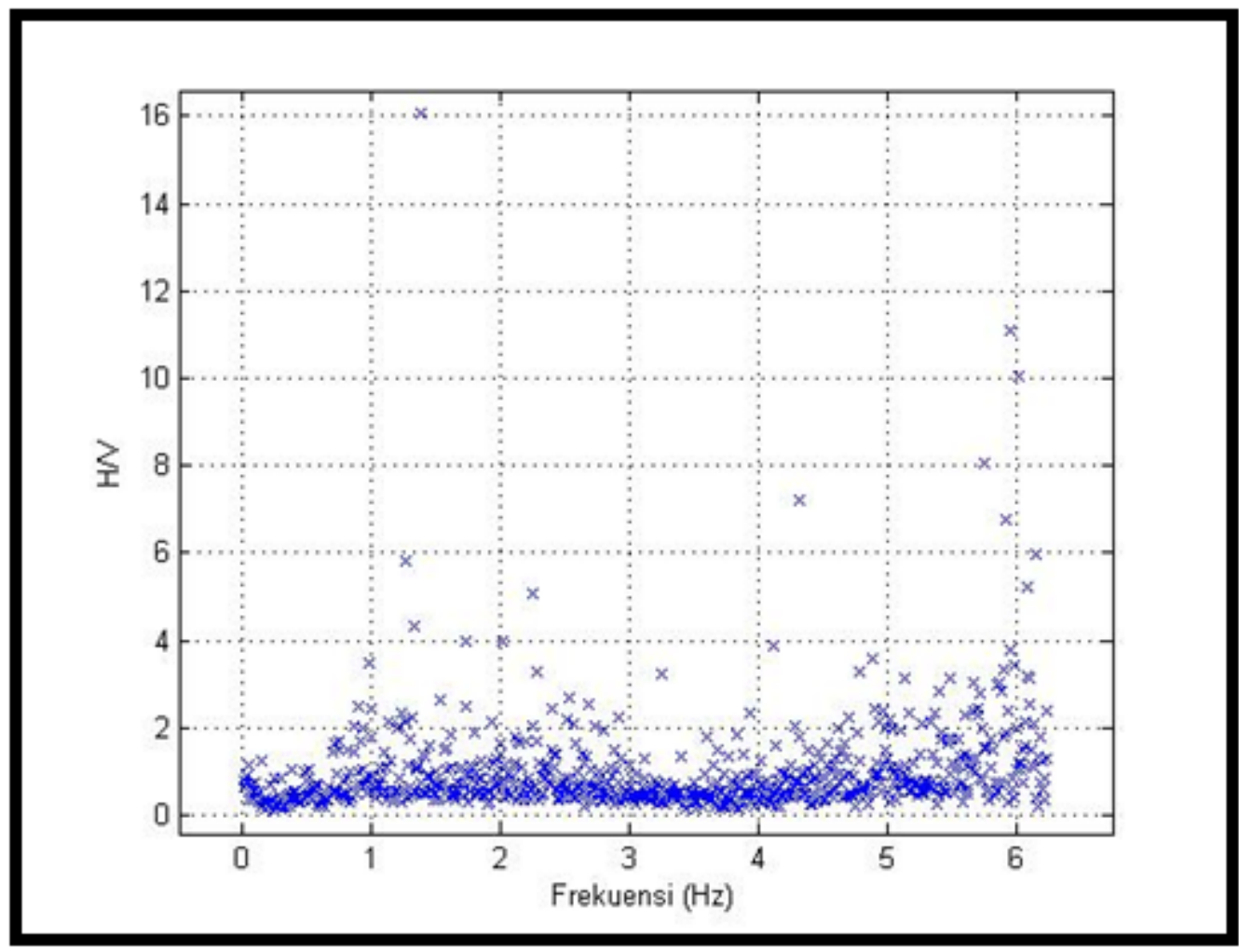

Gambar 7. Persebaran data hasil FFT pada frekuensi $350 \mathrm{~Hz}$

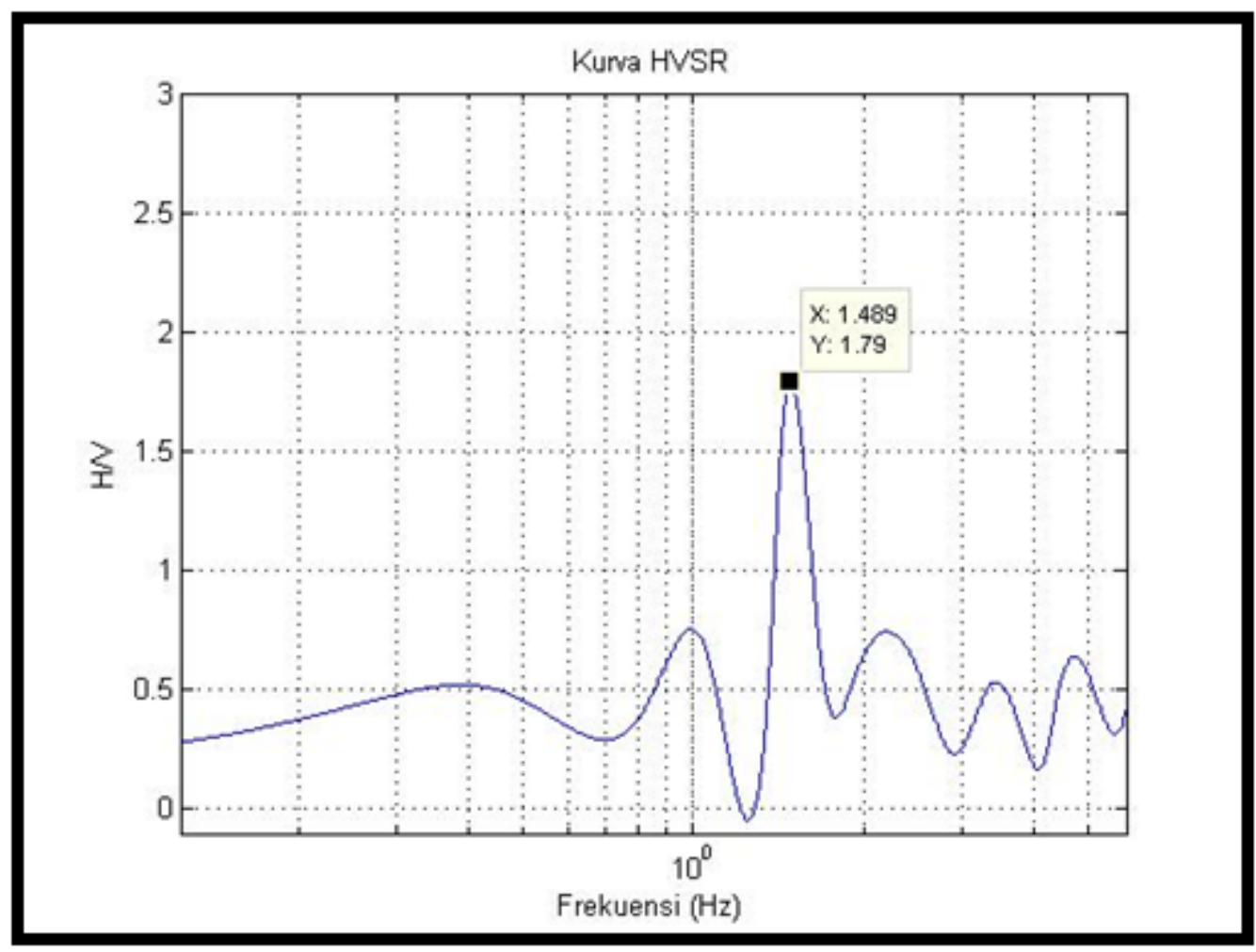

Gambar 8. Kurva HVSR 


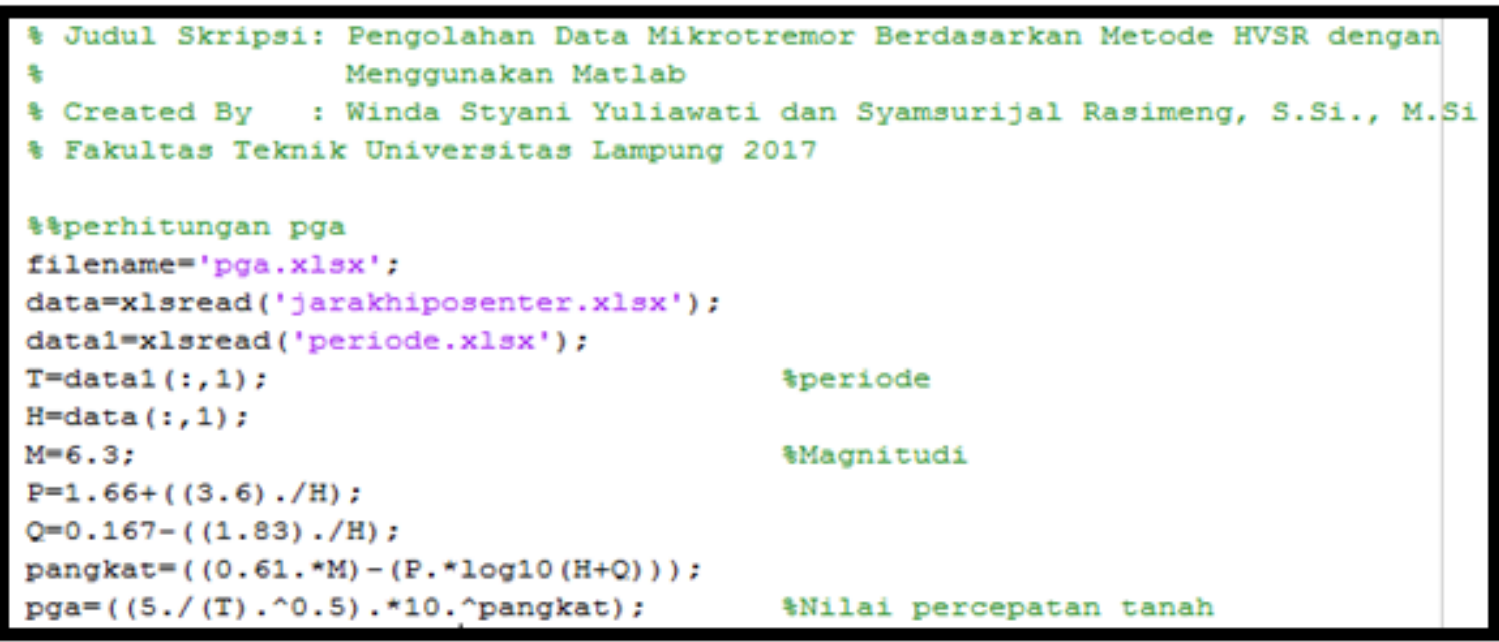

Gambar 9. Script pengolahan nilai PGA

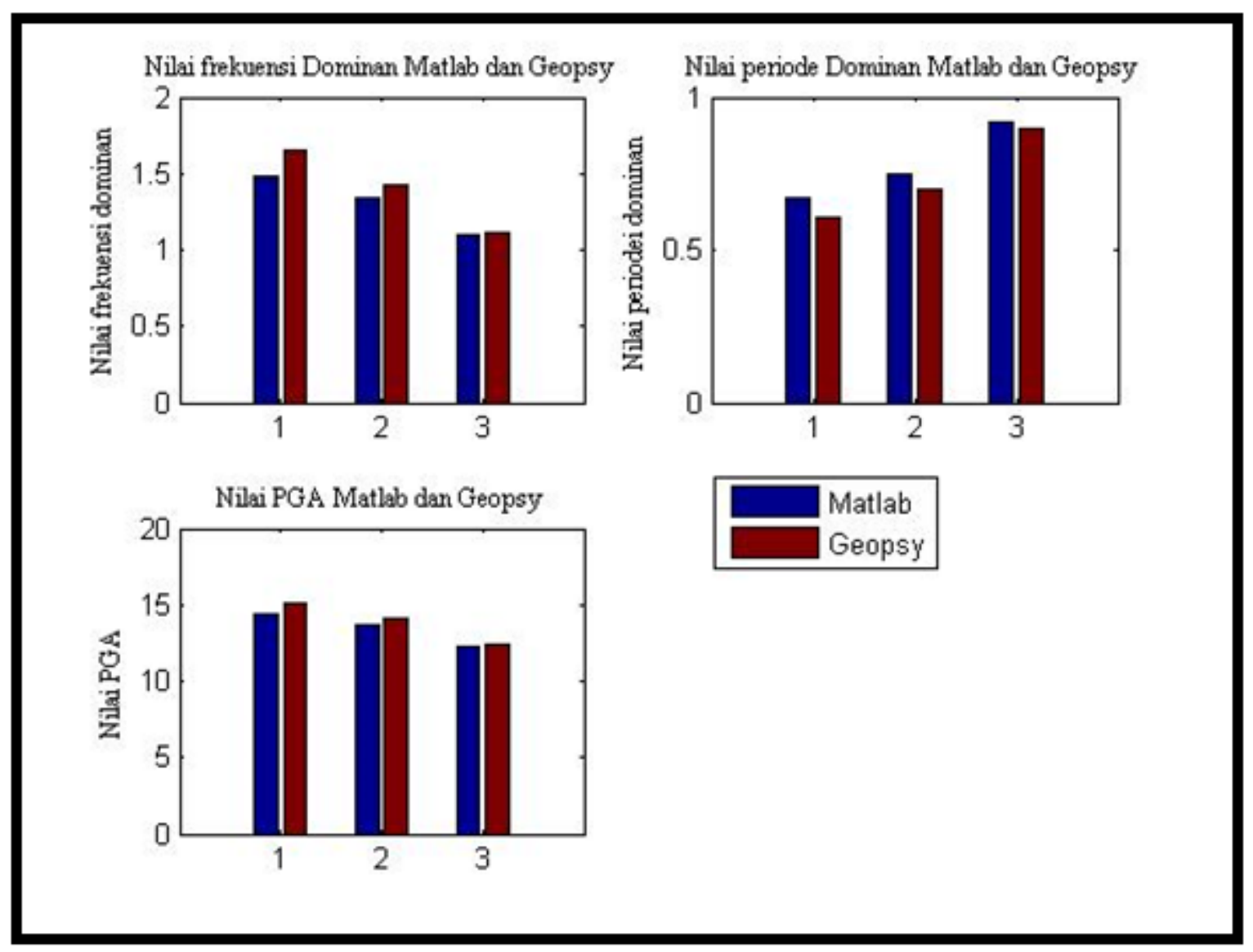

Gambar 10. Hasil nilai pada Matlab dan Geopsy 